\title{
Combined DRIFTS and DFT Study of CO Adsorption and Segregation Modes in Pt-Sn Nanoalloys
}

\author{
Qing Wang ${ }^{1}$, Didier Tichit ${ }^{1}$, Frederic Meunier ${ }^{2,}{ }^{,}$, Hazar Guesmi ${ }^{1, *}$ \\ ${ }^{1}$ Institut Charles Gerhardt Montpellier, UM/CNRS/ENSCM, 240, Avenue du Professeur \\ Emile Jeanbrau, 34090 Montpellier, France \\ *E-mail : hazar.guesmi@enscm.fr \\ ${ }^{2}$ Univ Lyon, Université Claude Bernard Lyon 1, CNRS, IRCELYON, 2 Av. Albert Einstein, 69626 \\ Villeurbanne, France. \\ *E-mail : frederic.meunier@ircelyon.univ-lyon1.fr
}
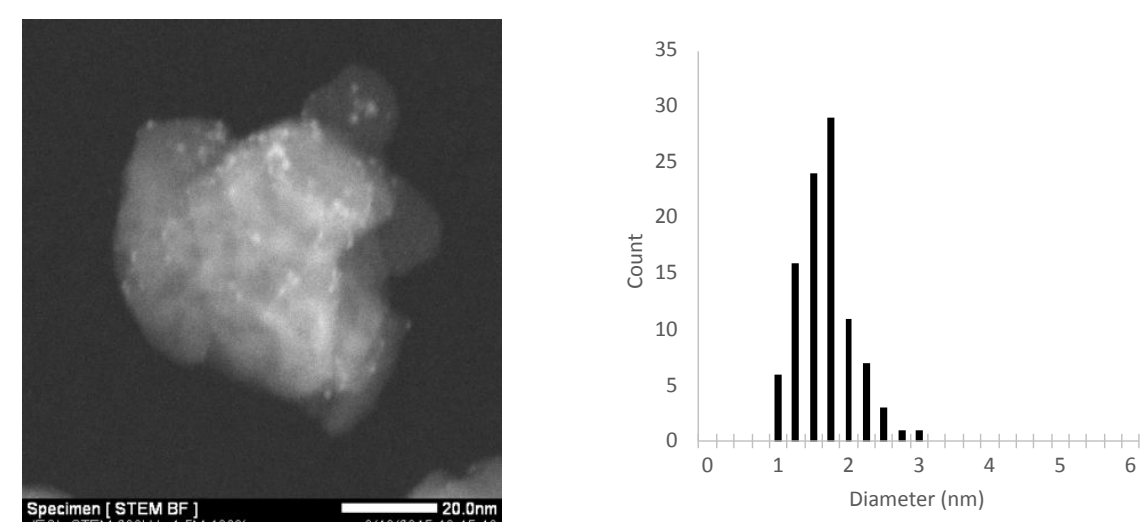

Figure S1: STEM picture and particle size distribution of Sn-rich Pt-Sn nanoparticles supported onto $\mathrm{Y}-\mathrm{Al}_{2} \mathrm{O}_{3}$.
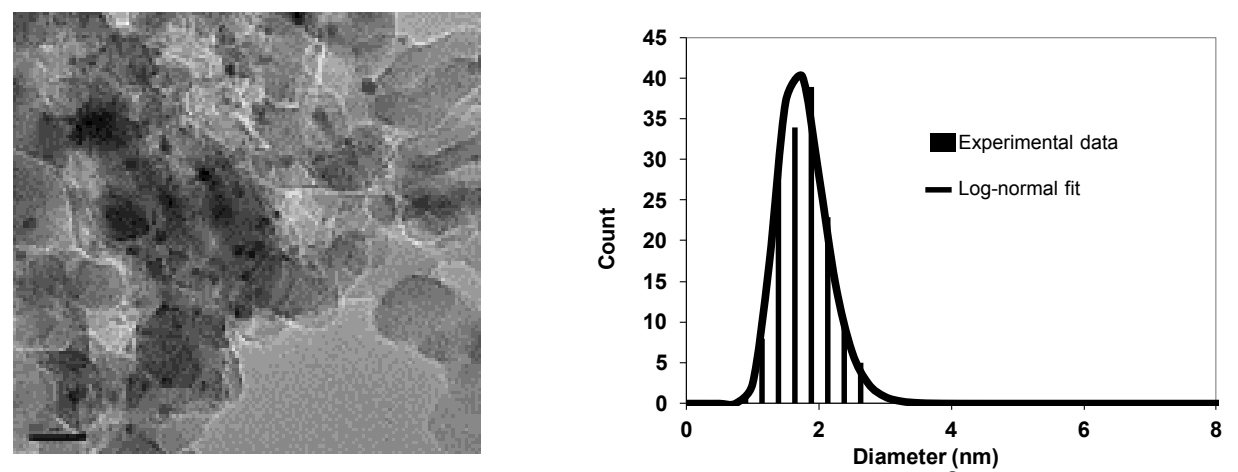

Figure S2: TEM picture and particle size distribution of Pt nanoparticles supported onto $\gamma$ $\mathrm{Al}_{2} \mathrm{O}_{3}$. Black scale bar represents $20 \mathrm{~nm}$. (Reprinted from reference 24, Moscu et al., Chem. Commun. 2014, 50, 8590-8592, Reproduced by permission of The Royal Society of Chemistry) 

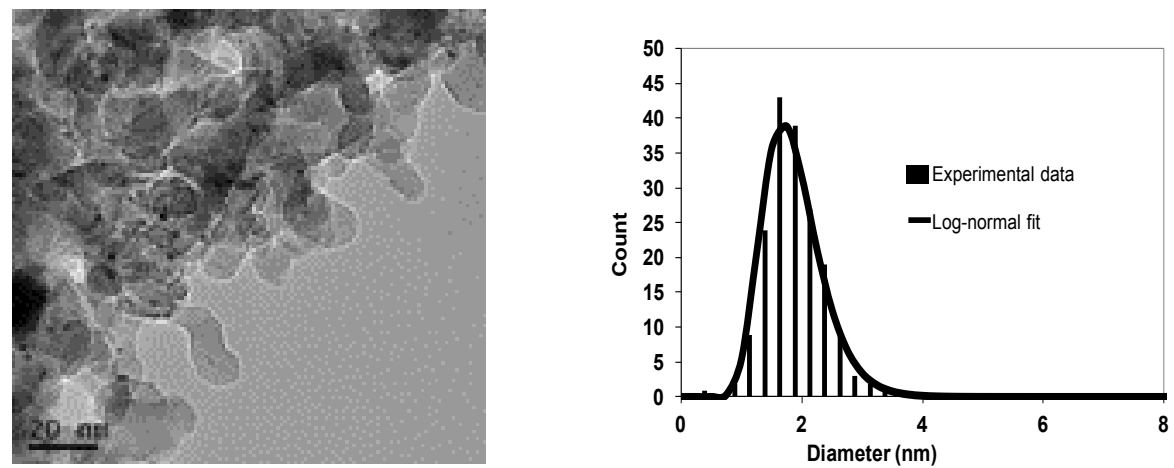

Figure S3: TEM picture and particle size distribution of Sn-poor Pt-Sn nanoparticles supported onto $\mathrm{Y}-\mathrm{Al}_{2} \mathrm{O}_{3}$. Black scale bar represents $20 \mathrm{~nm}$. (Reprinted from reference 24, Moscu et al., Chem. Commun. 2014, 50, 8590-8592, Reproduced by permission of The Royal Society of Chemistry). 